\title{
Long term management of a corporate GIS
}

\author{
TAI O. CHAN and IAN P. WILLIAMSON \\ Department of Geomatics, The University of Melbourne, Parkville, \\ Victoria 3052, Australia. \\ email: tch@sli.unimelb.edu.au and i.williamson@eng.unimelb.edu.au
}

(Received 30 December 1998; accepted 28 June 1999)

\begin{abstract}
The GIS literature abounds with strategies to guide the development of a corporate GIS as a single project but lacks discussion on the long term management of the GIS. This paper documents a recent study into GIS development in a state department over an 18-year period. It applies the productional perspective of GIS to model long term GIS development diagrammatically and identifies five patterns of GIS development. The outcomes reveal some long term characteristics of a corporate GIS, based on which a three-stage approach is developed to guide the long term development of an ideal corporate GIS.
\end{abstract}

\section{Introduction}

Managers are considered to be one of the key drivers in GIS development. Their characteristics and their management activities are important factors in the successful implementation of GIS in an organisation (Croswell 1989, Koller 1993, Engelken 1994 as quoted in Ferrari and Onsrud 1995). Successful GIS projects often require a shared understanding or vision of how the GIS will be used (Huxhold and Levinsohn 1995). Chan and Williamson (1996) further suggest that the visions held by members of an organisation have to be aligned to the dominant GIS vision of the organisation to drive the diffusion of GIS successfully.

In addition to the effort of managers, support from politicians, senior management and staff are also considered important in the process (Croswell 1989, Azad and Wiggins 1993, Budic 1994, Bundock 1996, Ventura et al. 1992 and DiSera 1993, both as quoted in Ferrari and Onsrud 1995). Campbell and Masser (1992) refer to this concerted support from managers and other members of an organisation as the organisational commitment. They also highlight the problem of sustaining the commitment for the whole life cycle of a GIS project, which could last from a few months to a few years depending on the scale of the project.

If sustaining commitment within such a short time span is a problem, imagine the problem faced by the managers who have to sustain the development of a corporate GIS at the end of the GIS project. There is virtually no investigation into this post-implementation aspect of the management of a corporate GIS in the literature apart from some discussions on the strategic placement of the GIS project in an organisation, and the routines of managing GIS personnel and operations (Huxhold and Levinsohn 1995).

This paper addresses the long term management of a corporate GIS by drawing on the results of a study of GIS development over an 18-year period in the 
Department of Natural Resources and Environment (DNRE) of the State Government of Victoria in Australia. The chronological development of DNRE's corporate GIS is modelled by the productional perspective of a corporate GIS (see $\$ 2$ below) (Chan and Williamson 1999) according to a set of pre-defined rules. From the resulting model, five patterns of development are identified. These patterns are then related to the nature of GIS visions, organisational commitment in terms of support from senior, middle and junior (line) managers, and the extent of integration of the GIS. Close examination of the model of DNRE's corporate GIS and the patterns of GIS development reveals some characteristics of a corporate GIS that enables a set of long term GIS management strategies to be developed.

In this paper a corporate GIS refers to a collection of all GIS capabilities in an organisation. Initially these capabilities may or may not be integrated, but ideally, in a mature working corporate GIS, they should be fully integrated serving all users.

\section{Field study of GIS development}

\subsection{Background}

In their discussion on the identities of a GIS, Chan and Williamson (1999) develop a productional perspective that views a corporate GIS as an integral part of the production process of an organisation. In such a corporate GIS, certain collections of GIS capabilities (GIS modules) have the function of directly generating the products and/or services required of the organisation. These modules are called business process GIS. The remaining GIS modules in the corporate GIS have a role of supporting the development and functioning of the business process GIS and are called infrastructure GIS. Both groups of GIS modules include the five generic elements of GIS, that is, data, standards, people, information technology and organisational setting (Chan and Williamson 1995).

Based on the productional perspective of GIS, Chan and Williamson (1999) developed a model to describe diffusion of a corporate GIS. They also tested their model by examining the development of DNRE's GIS over an 18-year period from 1979-1997. Not being the staff of DNRE, the authors were able to examine the case of DNRE objectively. The field study itself was conducted from February to July, 1997. In the six months, 34 managers of DNRE, past and present, were interviewed in 38 sessions. Some managers were identified beforehand but many were identified in the course of the interviews. The study focused on the development of GIS capabilities in DNRE in general and not the uptake of the technology by individuals.

DNRE is an end product of successive government restructuring in 1979-1997 to amalgamate departments with responsibilities for related business functions into larger, more cost-effective departments. The very dynamic organisational setting, experienced by DNRE and its precursor departments in the period, epitomises that of many modern organisations deeply affected by economic rationalism. Therefore the field study can help to shed light on the issues of sustaining the long term development of corporate GIS in a typical dynamic organisational setting. This is begun in the next section by documenting some key observations made in the study.

\subsection{Modelling development of DNRE's corporate GIS}

Using the productional perspective of GIS it is possible to model the dynamics of development of DNRE's GIS in 1979-1997 diagrammatically. This is achieved by grouping the GIS capabilities developed by DNRE and its precursor departments over the years into modules of infrastructure GIS and business process GIS. The 
chronological order of these modules and their relationships in the development process are modelled according to a set of pre-defined rules described below. Figure 1 illustrates the outcome of the modelling exercise. It provides a high level view of the evolving structures of the corporate GIS of DNRE and its precursor departments in terms of the two types of GIS modules. It also reveals several patterns of GIS that may have implications for the long term management of a corporate GIS.

\subsection{The rules for modelling}

In figure 1 the thick black arrow at the $x$-axis indicates the direction of the passage of time. Anything developed earlier is located to the left of those developed later. White rectangular boxes mark the periods of existence and the temporal relationships between DNRE and its precursor departments. These departments are named in Italics. The key business functions of the departments or their business units are shown in alternating light and dark grey bands and labelled in bold in figure 1.

A clear horizontal and a clear vertical oval represent the basic modules of infrastructure and business process GIS respectively. A vertical oval with dots in it represents a set of specialised GIS products or services that an infrastructure GIS provides to other GIS modules, infrastructure and/or business process. In case a horizontal oval has one or more vertical ovals resting on it, this represents an infrastructure GIS that supports one or more business process GIS. When a horizontal oval originating from a vertical oval on its left, this indicates that a business process GIS has acquired an additional role of an infrastructure GIS. A horizontal oval that links end-to-end with others represents a significant change in the way the infrastructure GIS concerned is managed. A hatched horizontal strip stands for a period of no physical GIS development, which may be due to non-supportive managers or the fact that GIS awareness is being cultivated in the organisation.

Only those business process GIS that are essential in demonstrating the structure of the corporate GIS and the patterns of GIS development are included. Others have been left out to simplify figure 1 .

\section{Patterns of GIS development}

Examination of the evolving structure of the corporate GIS of DNRE and its precursor departments in figure 1 reveals that the development of a corporate GIS starts in individual business functions of an organisation. In the early stage, development of GIS modules tends to be independent among business functions residing in the same or different organisations. Over time, as the organisations amalgamate, closer interactions among business functions lead to the development of links between GIS modules in different business functions. This results in some integration in the corporate GIS. In the process new business units are formed to manage and make better use of the technology. The technology and the organisation are moulded to match each other.

Closer examination of figure 1 also reveals five patterns of GIS development, namely, dormant, opportunistic, systematic, opportunistic-infrastructure and opportunistic-business process. Dormant indicates no physical GIS development. Opportunistic indicates development of GIS modules that is ad hoc and uncoordinated, and systematic, structured and well planned. A module of infrastructure GIS is developed 


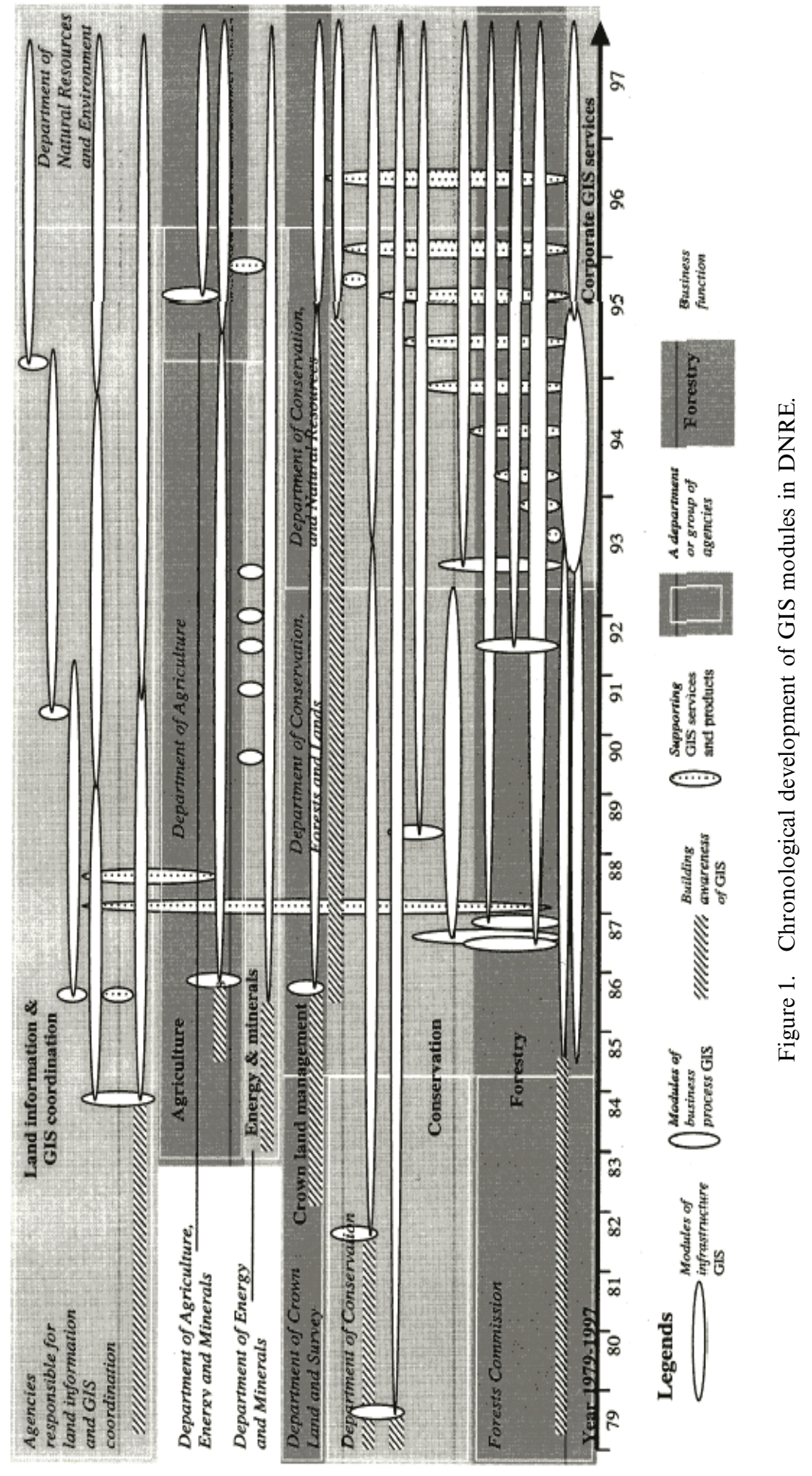


prior to the development of modules of business process GIS in the opportunisticinfrastructure pattern, and vice versa in the opportunistic-business process pattern. Each pattern is described in detail below with examples from DNRE.

\subsection{The dormant pattern}

The dormant pattern is a pattern in which there is no obvious development of GIS despite stakeholders' awareness of the value of GIS. This is to be distinguished from the normal gestation period in which GIS advocates prepare the organisation for GIS introduction by educating the stakeholders about the value of GIS and lobbying for their support.

A good example is the exceptionally long period that precedes GIS development in the Parks and Reserves Branch of DNRE (the horizontal oval at the upper right corner in figure 2). This period lasted for about ten years in the precursor organisation of the National Parks Services (NPS) in the Department of Conservation, Forests and Lands and the Department of Conservation and Natural Resources. The period is represented by a very long hatched horizontal strip that overlaps with a period of intense GIS development activities in other agencies in the same precursor departments.

For many years since 1985 the Director of NPS had a vision of realising the national parks objectives by investing in the physical improvement of parks and their services, and was generally against investing in computer or information management systems. This became the dominant GIS vision (Chan and Williamson 1996 ) adopted by managers throughout the organisation. Despite the strong demand for recreation plans and maps, NPS had resisted investing in GIS-based mapping technology. Any GIS capabilities introduced by innovative members of staff had limited impact on the overall business processes and were quickly forgotten when the staff member moved on. It was not until 1995, after the appointment of a new Director who was aware of the value of GIS, that NPS/Parks and Reserves Branch started to consider investing in GIS seriously. For more than a decade, the old Director's vision stifled any supportive GIS vision among the middle and junior managers. As a result there was no grass-root leadership and GIS development was delayed in NPS/the Parks and Research Branch.

\subsection{The opportunistic pattern}

In the opportunistic pattern the managers concentrate on developing independent modules of infrastructure GIS and/or business process GIS for their respective business units. They are not concerned with the uptake of the technology elsewhere in the organisation. This pattern is typically found in the early phase of GIS development in an organisation or when senior management holds a laissez faire attitude towards GIS development. If unchecked, this pattern would eventually create a corporate GIS that is made up of islands of GIS technology.

A good example of the independent development of GIS capabilities in 1979-86 in the wildlife conservation and flora conservation programs in the Department of Conservation. The middle and line managers in charge of the two conservation programs recognised the need to develop a computer system to manage the distribution data of the plants and animals in Victoria. This resulted in two independent modules of business process GIS (labelled as 'Wildlife Atlas' and 'Simple GIS to manage Floral Database' respectively in figure 2). These business process GIS eventually developed into two modules of PC-based infrastructure GIS that supported 

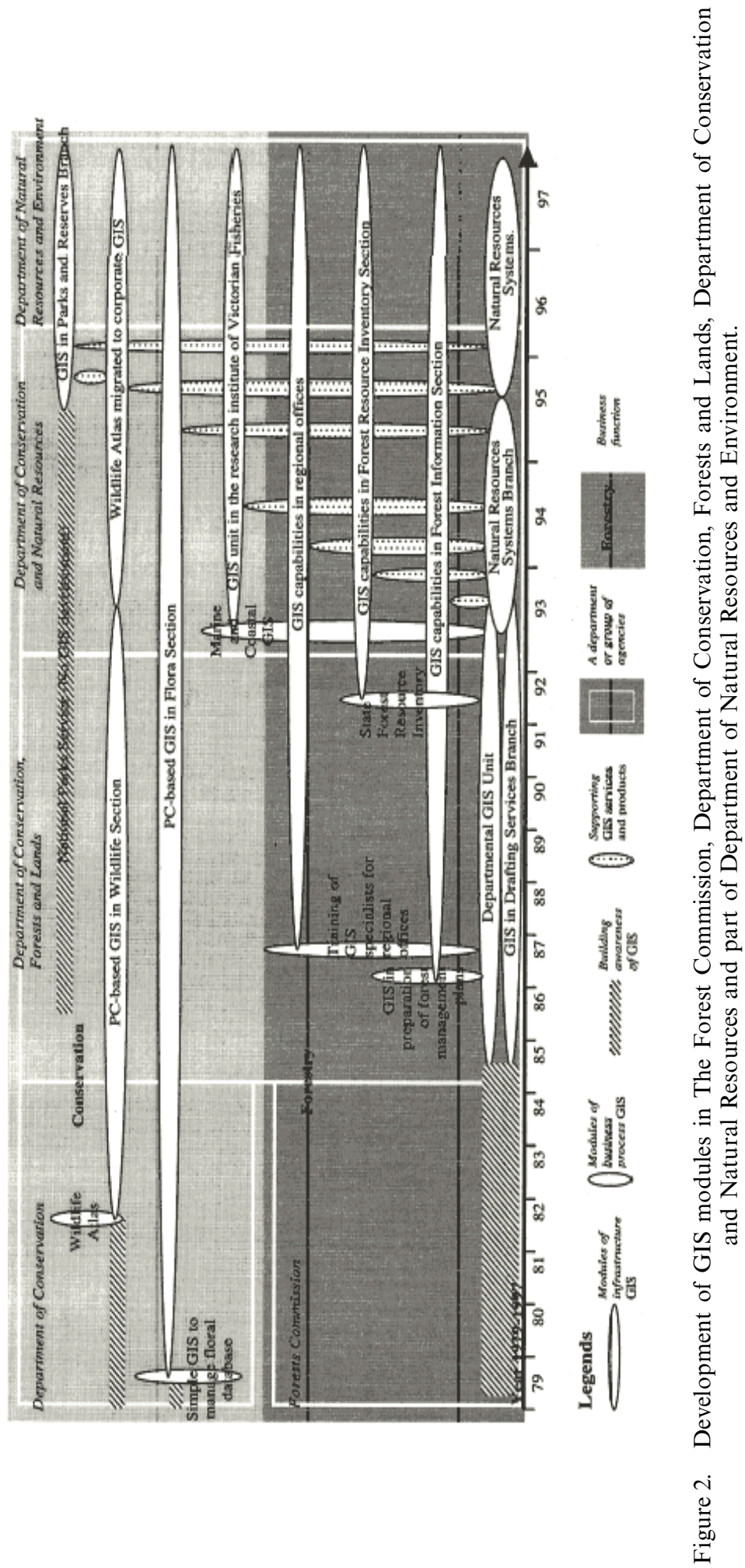
other GIS activities in the two conservation programs. After the amalgamation of Department of Conservation and the Forests Commission into the Department of Conservation, Forests and Lands, the managers continued to develop the GIS modules independently of the corporate GIS unit.

\subsection{The systematic pattern}

In the systematic pattern managers develop modules of infrastructure GIS and business process GIS in a well-planned and integrated manner to serve a wider community of users. To achieve the objective these managers are prepared to promote the uptake of GIS elsewhere in the organisation outside their business units. This pattern is typically found in an organisation where senior management recognises the importance of GIS and is leading and supporting the process of GIS development.

One example involves an information technology (IT) manager of the Department of Energy and Minerals (figure 3), another precursor department of DNRE. In 1983-1986 a series of studies and trial projects were conducted with limited success to automate service delivery in the department. Based on these experiences the IT manager advocated the development of an integrated department wide GIS called the Geological Exploration and Development Information System (GEDIS) in 1986. This system aimed at integrating data from different business functions in the department to allow potential local and overseas investors easy access to mining and exploration information.

As the system was seen as an integral part of the core business of the department and matched the business vision of the chief executive officer, it gained support from managers at all levels and in all divisions of the department. The State Government also provided financial support to the system in 1987 because of the system's value in facilitating mining investment from overseas and interstate.

As a result, the IT manager hired a project manager and staff with computer and GIS expertise, acquired GIS hardware and software, and drew data from different divisions in the department. A module of infrastructure GIS (labelled as 'GIS unit in Department of Energy and Minerals-GEDIS' in figure 3) was established simultaneously with the development of the first module of business process GIS, namely, the Tenement Management System, which was completed in 1990. By 1993, four more integrated core modules of business process GIS were added to GEDIS as planned.

As GEDIS was being developed, the department was restructured a number of times. Each time, the middle and line managers were able to convince the new senior management to support the project, keeping GEDIS as an integrated corporate GIS of the department. In 1995 the department amalgamated with the Department of Agriculture, another precursor department of DNRE. The new corporate GIS then comprised the fully integrated GENAMAP ${ }^{\circledR}$ based GEDIS, and the incompatible, loosely integrated $\mathrm{ARC} / \mathrm{INFO}^{\circledR}$ based GIS capabilities of the Department of Agriculture. Rather than integrating the two systems using a set of arbitrarily chosen standards, a working arrangement was made, in which the original GIS unit of the Department of Agriculture looked after strategic development of GIS in the new organisation while GEDIS provided general technical GIS support. The outcome was a new corporate GIS that was no longer fully integrated.

\subsection{The opportunistic-inf rastructure pattern}

In the opportunistic-infrastructure pattern managers, unlike those in the systematic pattern, can only secure short term support from senior management to develop an 


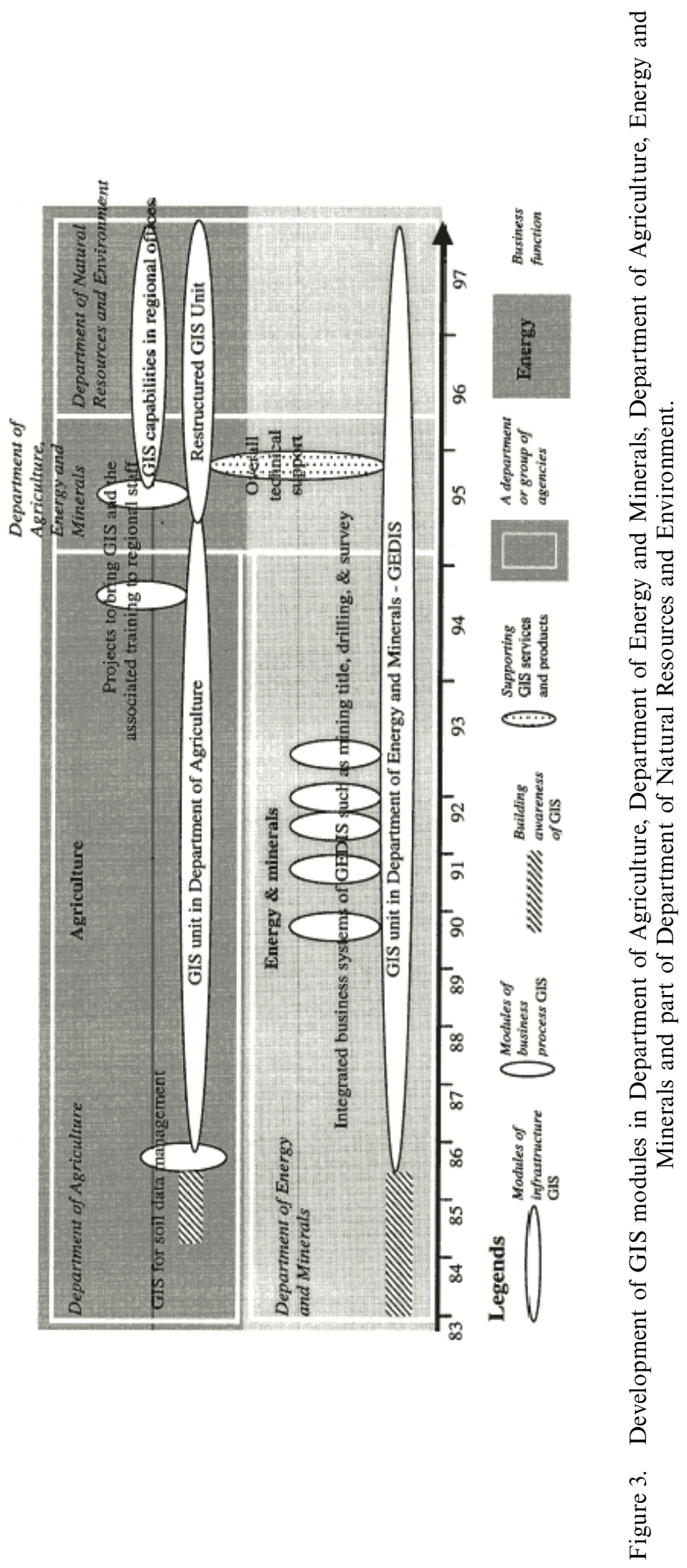


integrated GIS for the organisation. Long term support from senior management is uncertain. However these managers are prepared to lobby for additional support and resources from users both within and without the organisation to sustain the development of the corporate GIS.

There is only one example of the opportunistic-infrastructure pattern in DNRE, which involves the Department of Conservation, Forests and Lands (DCFL, centre of figure 2). With the help of a group of middle and line managers in the Forests Service Division in DCFL, the Director of Conservation who was a member of the senior management team and a pioneer in GIS and remote sensing, convinced senior management to create a module of infrastructure GIS (labelled as 'Departmental GIS Unit') in 1985. The module, which would be located in the Conservation Division and overseen by a special GIS steering committee, was initially staffed by a GIS manager employed in the same year.

The GIS manager had a vision of developing a department wide and state wide GIS. The support of senior management only provided a set of basic GIS software and hardware. There was no regular funding for the continual development of the one-person infrastructure GIS. In order to get the funding required, the GIS manager undertook to provide mapping products and services to the managers of the eighteen regions of the department, secured two-years funding, and started recruiting computer and application scientists. The module of infrastructure GIS in DCFL started to grow.

In 1986 the Director of Conservation retired. The infrastructure GIS was put under the charge of a middle manager in the Forests Service Division. The forestry manager, who recognised the value of digital data and had assisted the Director of Conservation in the creation of the GIS module, provided resources for the GIS manager to pursue his vision of developing both a department wide and a state wide GIS.

In 1987 the forestry manager also prompted the application of GIS to preparing forests management plans (see business process GIS entitled 'GIS in preparation of forest management plan' in figure 2). This provided a regular income to support the growth of the infrastructure GIS. In the same year, the GIS unit started to help regional offices to acquire their own GIS hardware and software, and to train their own GIS technicians (see business process GIS entitled 'Training of GIS specialists for regional offices' in figure 2). Based on the standards laid down in the departmental infrastructure GIS, these regional GIS technicians helped to develop regional infrastructure GIS that continued to use the data and services provided by the departmental one.

However senior management of DCFL still did not recognise the full potential of GIS and provided limited funding and policy guidance. At that time, the Drafting Services Branch in the department had also acquired its GIS-based mapping capabilities. To realise the vision of developing a department wide GIS, the GIS manager continued to expand the departmental infrastructure GIS. This was achieved by a strategy of undertaking projects from both inside and outside the department. While the infrastructure GIS supported the development of these projects (business process $G I S)$, the GIS capabilities developed for the business process GIS were fed back to support the development of the infrastructure GIS in return. Though the GIS manager left the department in 1990 to pursue his vision of a state wide GIS, the successor continued with this symbiotic strategy to develop the departmental infrastructure GIS.

DCFL was restructured into the Department of Conservation and Natural 
Resources in early 1993. Senior management recognised the duplication of GIS services between the departmental infrastructure GIS and the Drafting Services Branch, and merged the two to form a new business unit called Natural Resource Systems Branch. As a result, DCFL's infrastructure GIS grew in 8-years time from a 1-person unit to a major business unit that housed ten to twelve GIS specialists, six remote sensing staff and a 25-member cartographic output group in 1993. However policy guidance from senior management was still lacking. It was due to the persistence of a professional staff in the Natural Resource Systems Branch, which led the development of a central Corporate Geospatial Data Library. The Library was to standardise, warehouse and distribute compliant geospatial data and serve as a first step to integrate the diverse GIS data resources in the department.

As more business units developed their own modules of infrastructure GIS, the National Resource Systems Branch adapted by providing specialised GIS products and services (vertical ovals with dots in figure 2) to these infrastructure GIS. The products and services, which ranged from simple consultations, through data capture/analysis/management or map production to the development of an entire system, form the links between the departmental infrastructure GIS and other GIS modules in the organisation. These links gave the corporate GIS a significant degree of integration.

\subsection{The opportunistic-business process pattern}

The opportunistic-business process pattern is similar to the opportunistic-infrastructure pattern and is driven by managers of similar characteristics. However, unlike the latter pattern, these managers cannot secure initial support from senior management. Long term senior guidance and funding are also uncertain. As a result, the managers have to initiate the GIS development process by first developing a module of business process GIS using whatever resources they can use. Later GIS modules are then built on this initial module.

Sixteen out of the nineteen cases of GIS development in DNRE illustrated in figure 1 conform to this pattern which is by far the most common pattern. Examples include the 'GIS unit in the research institute of Victorian Fisheries' in the Department of Conservation and Natural Resources (figure 2), and the 'GIS unit in the Department of Agriculture' (figure 3). The following paragraphs describe the latter example in detail.

To ensure its continued survival the manager of Environmental Science Unit (ESU) had a vision of re-engineering the management of the state's soil data with GIS to better serve the agriculture community. With the support of the immediate supervisor, the manager acquired the necessary hardware and software and built a module of business process GIS to manage soil data/maps in ESU in 1986 (figure 3). The manager then marketed the GIS technology to regional colleagues in the department to promote the use of the digital soil data.

In 1987 using Federal funding that encouraged the use of soil data to improve agricultural practices, the manager undertook joint GIS projects, that is, modules of business process GIS, with regional staff. This cooperation led the module of business process GIS in ESU to acquire an additional role of an infrastructure GIS. Unlike the departmental infrastructure GIS in DCFL (\$3.4), the manager kept the GIS module in ESU small, transferring the data and technology back to the clients in the regions on completion of the projects. There was virtually no control on how the clients should develop their GIS capabilities. 
Senior management's involvement had been minimal until 1992 when a new head of department (Secretary) took over. The Secretary was conscious of the value of information in general, and GIS in particular. The GIS module in ESU was restructured to a departmental infrastructure GIS to give it a more strategic and state wide focus. A department wide GIS strategy was introduced in 1993-4. With the introduction of a Wide Area Network in 1994, the departmental infrastructure GIS introduced PC-based GIS to the regional offices together with some basic data to promote the use of the technology. In this way modules of infrastructure and business process GIS were gradually developed in the regions based on the standards set by departmental module. By 1995 there was some integration in the corporate GIS of the Department of Agriculture.

\section{Characteristics of GIS development patterns}

The last section describes five patterns of GIS development identified from the case of GIS development in DNRE in 1979-1997. Each pattern represents one approach of GIS development adopted by the managers driving the process. Based on the context of GIS development described, each pattern can be characterised by a unique combination of the extent of integration of the corporate GIS, the nature of the GIS visions of these managers and the organisational commitment.

In this paper the extent of integration of the corporate GIS varies along a continuum between no integration and full integration. The extent of integration between the two extremes is referred to as varying.

The GIS visions of managers in an organisation vary (Chan and Williamson 1996) and can be classified as supportive and non-supportive in the case of DNRE. A non-supportive vision suggests that there is no business need for GIS. A supportive GIS vision can be further sub-divided into two types, namely, restricted and broad, depending on whether the managers aim at developing a GIS that serves a specific business unit or a wider community such as a division, a department, or the entire state/nation.

Organisational commitment in the case of DNRE refers to the managerial support from each of the three basic levels of administrations in the organisation-senior, middle and junior/line. The support includes inputs of resources, leadership, policy, and lobbying/marketing effort. In the course of the interview some respondents in DNRE reported that it took at least the concerted effort of managers in both the middle and junior levels to sustain the development of GIS. While the junior/line managers knew the business processes and the technology, they need the resources controlled by the middle managers to secure and develop the technology. Resources, though acknowledged as important in GIS development (Budic 1993, Arnaud et al. 1996), do not stand out as crucial as the support from senior or middle management, or both. The experience of DNRE described in $\S 3.3-3.5$ suggests that junior managers, motivated by their GIS visions and supported by their supervisors, can mobilise resources from both inside and outside the organisation to sustain GIS development.

The characteristics of each of the five patterns in terms of the three attributes discussed above are summarised in table 1 and described in detail in the next two sub-sections.

\subsection{The dormant, systematic, and opportunistic patterns}

In the dormant pattern there is neither supportive GIS vision nor managerial support for GIS development in an organisation. As a result there is no corporate 
Table 1. Characteristics of the five patterns of GIS development.

\begin{tabular}{llcccc}
\hline $\begin{array}{l}\text { Patterns of GIS } \\
\text { development }\end{array}$ & \multicolumn{1}{c}{$\begin{array}{c}\text { Nature of the } \\
\text { GIS vision }\end{array}$} & \multicolumn{2}{c}{$\begin{array}{c}\text { Managerial support of the } \\
\text { GIS vision }\end{array}$} & $\begin{array}{c}\text { Integration of } \\
\text { corporate GIS }\end{array}$ \\
\hline & & Senior & Middle & Junior & \\
Dormant & Non-supportive & No & No & No & No \\
$\begin{array}{l}\text { Systematic } \\
\text { Opportunistic }\end{array}$ & $\begin{array}{l}\text { Supportive and broad } \\
\text { Supportive and } \\
\text { restricted }\end{array}$ & Yes & Yes & Yes & Full \\
$\begin{array}{c}\text { Opportunistic- } \\
\text { infrastructure }\end{array}$ & $\begin{array}{l}\text { Supportive and broad } \\
\text { Opportunistic- } \\
\text { business process }\end{array}$ & Supportive and broad & Uncertain \\
but early & Uncertain & Yes & Yes & Yes & Varying \\
\hline
\end{tabular}

GIS and no integration. Even when an innovative member of staff somehow adopts the technology personally, it will be shelved and forgotten as the staff member moves on.

In the four remaining patterns, there are both supportive GIS visions and managerial support that result in a corporate GIS that is integrated to a different extent in each case. One common condition for these four patterns is the concerted support from middle and line managers. This matches the experience of some respondents in DNRE as described above.

In the systematic pattern the GIS development process is structured and well planned, with a common broad GIS vision for a department wide GIS and concerted managerial support from all administrative levels, resulting in a fully integrated corporate GIS. Apart from the crucial bottom-up support of the middle and line managers, the senior managers provide the all-important policy guidance to integrate the development of GIS capabilities. This condition for the systematic pattern matches that of the process model of internal corporate venturing (Burgelman 1988) which prescribes that the overall success of a new internal venture in a company relies on complementary activities of managers at different levels in the company.

The opportunistic pattern is opposite to the systematic pattern in several ways. Typically the former is driven by the restricted visions of middle and line managers and lacks any kind of senior management support or guidance. The corporate GIS which is developed in an uncoordinated manner, is not integrated.

All three patterns of GIS development discussed so far assume a consistent set of GIS visions and managerial support. However classic organisation theories view an organisation as a means of achieving some common goals through people (Rogers and Agarwala-Rogers 1976, Schein 1980). In the long term, as staff move on or as the organisation is restructured, the goals of the organisation and the GIS vision of managers will change. This makes long term concerted managerial support (or the lack of it) for GIS, particularly that of senior management, uncertain in any organisation. Therefore, in the long term, the dormant, systematic and opportunistic patterns of GIS development are not sustainable.

For example, if GIS is the technology that business units in an organisation require to improve their products, services and productivity, any responsible senior management will eventually have to pull the organisation out of the dormant pattern and invest in GIS. This will happen somehow in due course as in the example of 
the delayed GIS adoption by the Parks and Reserves Branch of DNRE mentioned previously.

In the case of the opportunistic pattern of GIS development, it will result in so much duplication and inefficiency that in the current trend of economic rationalism, senior management will demand better coordination and integration in due course. A good example is the merging of the GIS unit with the Drafting Services Branch of DCFL.

Though the systematic pattern of GIS development has the merits of more sharing and less duplication, it may not remain as the standard approach of GIS development for very long. It has its limitations, such as, disagreement among stakeholders and decreased organisational efficiency (Campbell and Masser 1995). Further, on completion of the project as initially planned, rather than funding the continual development of the GIS, senior management may opt to deploy resources to tackle more urgent organisational issues or to undertake other projects that have a higher priority. As a result, the corporate GIS may only be left with a recurrent maintenance budget, or even be required to charge for its products and services to earn its keep. In any case, it will be unable to cater for the full range of information needs of the organisation. This will force business units to develop their own GIS capabilities and the corporate GIS will no longer be developed in a systematic manner. The reluctance/inability to fully integrate GEDIS of the Department of Energy with Mineral and the GIS unit of the Department of Agriculture as the two departments amalgamated (\$3.3) shows that the systematic pattern is not sustainable in a dynamic organisational setting.

\subsection{The opportunistic-inf rastructure and opportunistic-business process patterns}

Unlike the previous three patterns, the opportunistic-infrastructure and the opportunistic-business process patterns do not assume consistent support from senior management. The latter two patterns take place when the middle and line managers work in a concerted manner to achieve a broad GIS vision, but with uncertain support from senior management-the typical organisational setting in the long term. Irrespective of the support from senior management, the middle and line managers secure the resources to realise their broad GIS vision by engaging in continuous proactive 'scavenging' activities (Burgelman 1988: 588) to obtain resources and to promote the technology, both inside and outside the organisation.

In the process, if they get some early input from senior management, they may develop a module of infrastructure GIS which is used to facilitate the development of other modules of business process GIS in the rest of the organisation. This early development of an infrastructure GIS forms the opportunistic-infrastructure pattern of GIS development.

If there is little or no initial support from senior management, the middle and line managers may make use of the limited resources from one or more business units to develop a small module of business process GIS, initially to satisfy the business needs of these units. The GIS module is also used to demonstrate the value of the technology to other stakeholders. As more managers or professional staff, particularly senior managers, recognise the value of GIS and become more supportive, the initial GIS capabilities are then used to support the development of other business process GIS, and thus assume an additional role/identity of an infrastructure GIS. This gives rise to the opportunistic-business process pattern of GIS development. Irrespective of which one of the two patterns the managers are in, they would 
develop the corporate GIS in a symbiotic manner in which infrastructure GIS and business process GIS support the development of one another. In theory, by having all the business process GIS in an organisation developed from a common infrastructure GIS, it would ensure that the GIS capabilities in the organisation are interoperable. In this way, it would seem that middle and line managers could still create a de facto integrated GIS without the sustained support from senior management. In practice this scenario seldom happens.

Medium to large organisations such as DNRE which has over 5000 people working in over 200 locations, have very diverse information needs. Each business unit will require a different combination of GIS capabilities that include data, standards, people with appropriate skills, and information technology. In terms of data and standards, different business units may require data of different themes and qualities. It will be difficult for a central infrastructure GIS to cater for the full range of data needs in a medium to large organisation such as DNRE. For example, in DNRE and its precursor, the Department of Conservation and Natural Resources (figure 2), the forestry staff needed forestry data while the fisheries staff needed fishery statistics to carry out their business functions. In DNRE's agricultural program, the departmental GIS unit ('Restructured GIS unit' in figure 3) normally worked with general data of state wide coverage for strategic management purposes, while the regional offices required more detailed operational data of a local coverage.

Even when a specific business function is well served by a central module of infrastructure GIS, that module still may not be able to provide the full range of GIS expertises needed in the business function. This is because, on the one hand, the perceived GIS needs of the business function change with time and the experience of using the technology. On the other hand, as the bureaucracy of the GIS unit grows, it may become less responsive to the GIS needs of business units. Either the projects proposed by business units are too small to arouse its interest, or the projects are beyond its expertise or the scope of the established data management policy. If GIS acquisition is tightly controlled, the business units may not get the GIS information products that they need. Otherwise, they will make use of the GIS capabilities of the central infrastructure GIS to develop their GIS expertise. The outcome is the creation of specialised multi-levelled infrastructure GIS within an organisation. Each business function develops its own module of infrastructure GIS to complement the capabilities of the central module and to meet long term business needs. This phenomenon of specialisation was first reported for IT infrastructure development in private companies (Weill and Broadbent 1994). Evidence from DNRE confirms that the same is applicable to GIS.

A good example is the Departmental GIS unit in DCFL (figure 2) that originally catered for all the GIS needs of the Forests Service Division in 1986-7. As the forestry staff gradually recognised the value of GIS in the core business of forest management, they found that DCFL's GIS unit was not providing the level of expertise and service the forestry staff needed. Therefore in 1992-3 the senior management of the Division decided to invest in its own GIS capabilities and created the Forest Information Section and the Forest Resource Inventory Section.

The Forest Information Section specialised in the business process of timber harvest modelling. Over the years, the Section evolved into a separate module of infrastructure GIS that provided specialised services, such as, purchasing specialist linear programming software (an example was the American timber yield forecasting software, FORPLAN) for forestry applications, providing timber harvest 
analysis and modelling services in support of forest planning activities, and producing sustainable timber yield forecast for forest management.

The Forest Resource Inventory Section focused on capturing forest resource data to serve the entire Division. Like the Forest Information Section, it also evolved into a separate module of infrastructure GIS. It provided specialised services, such as, purchasing of hardware and software best suited for data capture and rectification, capturing, maintaining and providing state wide hardwood forest resource data, specifying, negotiating and implementing data capture and compilation contracts, and providing advice and services of accessing and utilising the forest resource database.

At the same time, the two Sections still used data that were stored in the departmental spatial databases maintained by the departmental GIS unit. The Departmental GIS unit of DCFL still provided general GIS products and services that complemented the specialised GIS capabilities of the two Sections in Forests Service Division. The GIS products and services included purchasing of general GIS software and hardware, specifying, negotiating and implementing maintenance and system implementation contracts, collecting, purchasing and maintaining department wide core spatial datasets, developing standards for spatial data, and for hardware, software and communication, providing high quality maps, providing DIS help desk, and spatial database and information system development and maintenance services. Table 2 summarises the specialised services provided by infrastructure GIS developed at three different administrative levels in DNRE.

The specialised GIS products and services not only give rise to multi-levelled infrastructure GIS, but also serve as links among key GIS modules of a corporate GIS. Some links are tight as in the case when the central infrastructure GIS uses its

Table 2. Three levels of infrastructure GIS in DNRE.

Levels of infrastructure GIS

Department wide

Business function/division wide

Business process level
Type of services

Procurement and maintenance of GIS hardware and software, and department wide core GIS datasets.

GIS contract specification, negotiation and implementation.

Development of minimum enforceable data, hardware, software and communication standards for GIS.

GIS help desk and department wide spatial database and information system development and maintenance.

Procurement of specialised data, hardware and software.

Capturing and maintaining data of special themes, scales or coverages.

Specification, negotiation and implementation of special contracts.

Specific GIS help desk or development consultation services.

Procurement of application specific data, hardware and software.

Production of specialised data products, such as paper maps for specific themes/applications, CD-ROMs, 3-D images.

Providing modelling and spatial data analysis services specific to the business process in question. 
own system as a blue-print, designs and implements entire GIS modules, business process or infrastructure, on behalf of its clients. This implies that data, applications and expertise are transferable between the central GIS module and the GIS modules that its helps to create, and that the resulting corporate GIS is in effect fully integrated.

Other links are loose, meaning that individual GIS modules may adopt standards different from those of the central infrastructure GIS. In this case, the central infrastructure GIS provides only general services and products such as data capturing, certain data analysis procedures and production of specialist maps. Loose links imply little integration between the resulting corporate GIS.

Irrespective of whether it is the opportunistic-infrastructure or the opportunisticbusiness process pattern, it is the overall nature of these links that determines the extent of integration between the GIS modules. The tighter these linkages are in relation to a common set of standards, such as that provided by the infrastructure GIS, the better integrated is the corporate GIS, and vice versa. Neither one of the two patterns can guarantee full integration.

In short, by definition, there are few links, if any, in the dormant and opportunistic patterns of GIS development. Therefore these patterns do not generate integrated corporate GIS. The links in the systematic pattern are tight by design giving rise to a fully integrated corporate GIS. The uncertain nature of the links created by the opportunistic-infrastructure and the opportunistic-business process patterns suggests that a fully integrated corporate GIS is possible but not guaranteed.

\section{Long term characteristics of a corporate GIS}

Section 3 examines how DNRE's corporate GIS and its dynamics of development are modelled over an 18-year period using the productional perspective. Section 4 further examines the five patterns of GIS development in their respective organisational context in this extended period of time. Each pattern is then characterised by a set of attributes identified within the organisational context, which include the nature of the GIS vision, organisational commitment and the degree of integration of the GIS. The examinations have revealed some important long term characteristics of a corporate GIS that are described as follows.

Firstly, a corporate GIS is a dynamic and modular entity that is made up of basic modules termed infrastructure and business process GIS. Infrastructure GIS serve business functions in an organisation indirectly by facilitating the development of existing and new business process GIS. It is the business process GIS that deliver direct benefits to an organisation. This relationship is illustrated by the lack of standalone infrastructure GIS as in the case of DNRE and the very common occurrence of the opportunistic-business process pattern of GIS development in which business process GIS are developed first.

Secondly, in a medium to large enterprise, the corporate GIS tends to be a multilevelled entity. The business units are supported by a number of infrastructure GIS that progressively specialise to serve specific needs of the business units. The varied and changing information needs of the business units make it almost impossible to clearly define the long term composition or capabilities of a corporate GIS and its GIS modules and to develop such a corporate GIS systematically. The dynamic organisational setting only adds to the complexity of the process.

Thirdly, the GIS services and products provided by one infrastructure GIS to other GIS modules help to link the GIS capabilities in different business functions 
of an organisation together. The links can be tight or loose. Tight links in the form of common data model, format and sources, compatible/interoperable hardware and software produce a better-integrated corporate GIS. The best integration is achieved in a systematic pattern of GIS development in which all GIS capabilities are centrally determined. Integration is significantly weaker when one infrastructure GIS provides other GIS modules with products or services that do not conform to a common set of standards.

Fourthly, none of the five patterns of GIS development can guarantee successful development of that ideal integrated corporate GIS in the long term. By their nature, the dormant and opportunistic patterns are not conducive to integration. While the systematic pattern can ensure the development of such a GIS in the short term, it has been argued in $\S 4.1$ that it is not sustainable in the long term.

In the typical dynamic setting of an organisation in which sustained support from senior management is uncertain, the more sustainable patterns are the opportunistic-infrastructure and opportunistic-business process patterns, which involve middle and line managers 'scavenging' for resources to develop the corporate GIS. However, the variable nature of the links developed among different GIS modules suggests that while full integration of the corporate GIS is possible, it is not guaranteed.

\section{Implications for management of GIS}

The relationship between the two basic modules of a corporate GIS suggests that developing one central infrastructure GIS is not the Holy Grail. It is the business process GIS that directly deliver benefits. Development of both infrastructure and business process GIS should proceed in a complementary manner to realise the benefits as early as possible and to ensure that the technology stays relevant. This serves to meet the users' expectations and to sustain their support (Bundock 1996).

It is the concerted effort of managers with a broad GIS vision from different administrative levels in an organisation that drives the development of the ideal integrated corporate GIS. However in the long term, the normal dynamics in an organisation is such that the organisational commitment in terms of support of other managers, particularly that of senior management will fluctuate. Therefore to ensure that a corporate GIS will continue to develop in an integrated manner, the strategies adopted by managers driving the process should be flexible enough to adapt to the changing organisational commitment.

To be flexible, managers should recognise that it is the nature of the links among GIS modules that determines the extent of integration of the corporate GIS. Links are created primarily through strategies adopted in the systematic, opportunisticinfrastructure and opportunistic-business process patterns of GIS development, which capitalise on different extent of organisational commitment. Developing an integrated corporate GIS requires the creation of tight links among GIS modules by drawing on the strategies of the three patterns that match the prevailing organisational commitment. Based on the productional perspective of GIS and the experience of GIS development over an 18-year period in DNRE, figure 4 describes a three-stage approach to the long term development of a corporate GIS.

In the first stage a module of business process GIS is developed to generate direct and immediate business benefits to the organisation. This stage serves to raise the awareness of GIS in the organisation, and to demonstrate the value of GIS. This module may be developed through one or more pilot studies. In the process the GIS 


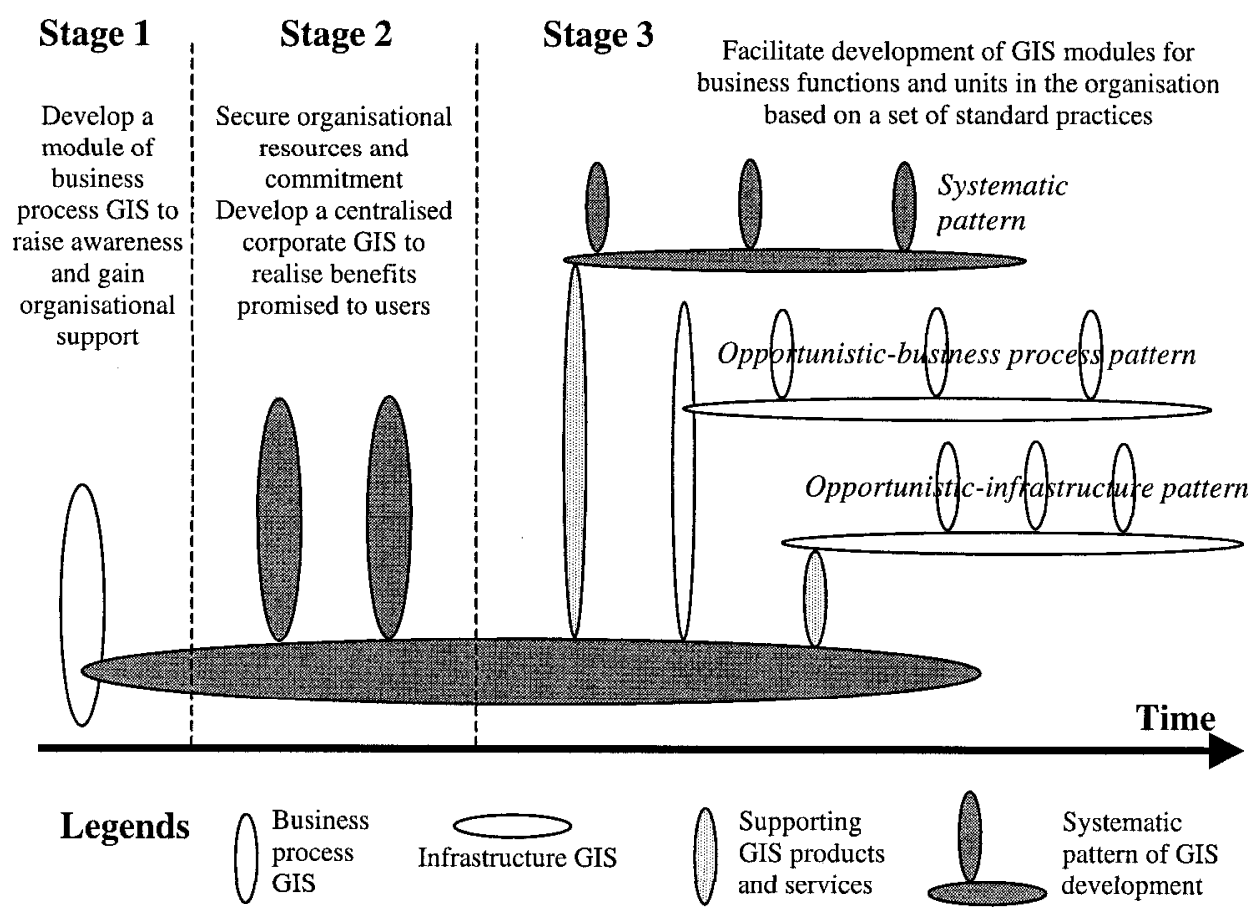

Figure 4. Three-stage development of a corporate GIS based on the productional perspective of GIS.

advocating managers lobby for funding and policy support from top management for a centralised integrated corporate GIS.

In the second stage, top management funding and policy guidance are secured. The detailed capabilities of the GIS modules of the corporate GIS are identified and defined as far as practical and implemented. Development of infrastructure GIS is tightly coupled to that of the business process GIS to ensure early delivery of benefits. For these two stages, there are many strategies in the literature to guide implementation (Azad and Wiggins 1993, Onsrud and Pinto 1993, Engelkan 1994, Vastag et al. 1994, Ferrari and Onsrud 1995, Somers 1996). The objective of this stage is to build a robust over-arching framework to guide GIS development in the organisation later on.

In the third stage, the emphasis of development of the corporate GIS is shifted from building the centralised entity to building GIS capabilities in business units. With the support from the centralised GIS, business units are encouraged to use GIS, and subsequently, to develop their own GIS modules (both infrastructure and business process) based on an over-arching framework. The process of GIS development in the business units may follow any one of the three patterns of GIS development, namely, systematic, opportunistic-infrastructure, and opportunisticbusiness process. The haphazard opportunistic pattern of development should be avoided.

In the process, links between the centralised GIS and the multi-levelled GIS capabilities in the business units are created ensuring that the latter are developed according to standard practices and communication architecture. In this way, 
integration of the growing corporate GIS is assured, while the users are catering for their own needs by driving the GIS development themselves.

The management of this stage is easier said than done. Special change agents (managers or business analysts) are required. Their duties are to liaise with business units, cultivate GIS advocates in business units, explain the corporate GIS strategy, help the units to identify their GIS needs and develop GIS modules using whatever capabilities that are available in the centralised GIS and in the rest of the organisation. These change agents would encourage business units to use resources from both inside and outside the organisation to meet their GIS needs. All these activities are to ensure that users are driving the development of the GIS capabilities they need and thus have ownership of the technology. In return the change agents will require the business units to adopt the corporate standard practices in the GIS modules so that whatever GIS capabilities developed are accessible to all users in the organisation. If this is proven impractical, new arrangement should be explored to ensure that proposed new capabilities are interoperable with that of the organisation.

In order to carry out their duties effectively, the change agents must have good general knowledge of the GIS technology and the GIS resources available both within and without the organisation. They must also be good communicators who understand or are prepared to learn how the organisational units do their businesses. Last but not least, they must also be conversant with the corporate IT/GIS/ information management strategy, and the approaches that can be followed to meet the corporate standard practices. This would mean keeping abreast with the development of the technology.

\section{Conclusions}

This paper reports the outcomes of a study of the development of GIS in the Department of Natural Resources and Environment (DNRE) over a period of 18 years. Based on the productional perspective of GIS, which disaggregates a corporate GIS into models of infrastructure and business process GIS, this paper models the chronological development of DNRE's corporate GIS and documented five patterns of GIS development. The patterns are called dormant, opportunistic, opportunisticbusiness process, opportunistic-infrastructure and systematic. Each pattern is then characterised by a set of attributes identified within the respective organisational context, which include the nature of the GIS vision, organisational commitment and the degree of integration of the GIS.

Some important long term characteristics of a corporate GIS are identified as follows:

- A corporate GIS is a dynamic and modular entity with infrastructure GIS supporting business process GIS. It is the business process GIS that deliver direct benefits to an organisation.

- The corporate GIS tends to be a multi-levelled entity with modules of infrastructure GIS relying on one another for specialised products and services. Therefore it is difficult to define the detailed composition of the corporate GIS beforehand.

- The specialised products and services provided by infrastructure GIS serve as links between GIS modules. These links can be tight or loose, giving the corporate GIS different degrees of integration. 
- None of the five patterns of GIS development identified can guarantee successful development of an ideal integrated GIS in the long term.

In view of the fluctuating organisational commitment to GIS over time, it is argued that GIS managers should adopt a flexible approach towards GIS development, focusing on the management of tight links between GIS modules to ensure the development of an integrated corporate GIS. A three-stage approach to long term development of a corporate GIS is proposed.

In the first stage, a module of business process GIS is developed to gain support from the rest of the organisation, particularly senior management, for GIS development. In the second stage, with support from senior management, a central corporate GIS is developed to build an over-arching framework to guide GIS development in the organisation in future. In the third stage, GIS development is encouraged in business units through any one of the three patterns of GIS development, namely, systematic, opportunistic-business process, and opportunistic-infrastructure, while ensuring that the GIS capabilities in the business units conform to the organisational standards. The duties and qualities required of the change agents to manage the process of GIS development in accordance with the three-stage approach is briefly discussed.

\section{Acknowledgments}

The authors wish to acknowledge gratefully the support of Land Victoria (LV) of the Victorian Government, the Land Information Centre (LIC) of the New South Wales Government, and the Australian Research Council (ARC) (Grant No. C19700324), in the preparation of this paper and the associated research. However, the views expressed in the paper are those of the authors and do not necessarily reflect the views of LV, LIC or ARC.

\section{References}

Arnaud, A. M., Vasconcelos, L. T., and Geirinhas, J. D., 1996, Portugal: GiS diffusion and the modernization of local government. In GIS Diffusion: The Adoption and Use of Geographical Information Systems in Local Government in Europe, edited by I. Masser, H. Campbell and M. Craglia (London, UK; Bristol, PA: Taylor \& Francis), pp. 111-124.

AzAD, B., and Wiggins, L., 1993, Institutional issues in the transfer of GIS technology to organizations: the people gone missing. Paper presented at the First Sharjah Conference on Geographic Information Systems and Applications (Sharjah, United Arab Emirates), 11 pages.

Budic, Z. D., 1993, Human and Institutional Factors in GIS Implementation by Local Government. PhD thesis, The University of North Carolina at Chapel Hill.

Budic, Z. D., 1994, Effectiveness of Geographic Information Systems in local planning. Journal of the American Planning Association, 60, 244-262.

Bundock, L., 1996, Factors that influence the success of a GIS implementation. In Proceedings of AU RISA' '96 (Hobart: AURISA '96 Hobart), pp. 48-57.

Burgelman, R. A., 1988, Managing the internal corporate venturing process. In Readings in the Management of Innovation, 2nd edition, edited by M. L. Tushman and W. L. Moore (New York, NY: HarperBusiness), pp. 585-602.

CAmpbell, H., and Masser, I., 1995, GIS and Organizations (London, UK; Bristol, PA: Taylor \& Francis).

Chan, T. O., and Williamson, I. P., 1995, Justification of GIS as an infrastructure investmentsome observations regarding GIS management in Victoria. In Proceedings of AU RISA '95 (Melbourne: AURISA '95), pp. 492-503. 
Chan, T. O., and Williamson, I. P., 1996, A model of the decision process for GIS adoption and diffusion in a government environment. In Proceedings of URISA '96 (Salt Lake City, Utah: URISA), pp. 247-260.

Chan, T. O., and Williamson, I. P., 1999, The different identities of GIS and GIS diffusion. International Journal of Geographical Information Science, 13, 267-281.

Croswell, P. L., 1989, Facing reality in GIS implementation: lessons learned and obstacles overcome. In Proceedings of the URISA '89 (Boston, Massachusetts: URISA '89), pp. 15-28.

EngelKen, L. J., 1994, Project management tips for AM/FM project planning and implementation. In Proceedings of the XVII Annual AM/FM International Conference (Denver, Colorado: AM/FM International), pp. 188-193.

FERrari, R., and OnSRUd, H. J., 1995, Understanding Guidance on GIS Implementation: A Comprehensive Literature Review, National Center for Geographic Information and Analysis, Technical Report No. 95-13.

Huxhold, W. E., and Levinsohn, A. G., 1995, Managing Geographic Information System Projects (New York, Oxford: Oxford University Press).

Onsrud, H. J., and Pinto, J. K., 1993, Evaluating correlates of GIS adoption success and the decision process of GIS acquisition. URISA Journal, 5, 18-39.

Rogers, E. M., and Agarwala-Rogers, R., 1976, Communication in Organizations (New York: Free Press).

ScheIn, E. H., 1980, Organizational Psychology (Englewood Cliffs, N.J.: Prentice-Hall).

Somers, R., 1996, Managing GIS: What do we really know? In Proceedings of the Conference on 'Managing Geographic Information Systems for Success' (Melbourne: Centre for Geographic Information Systems and Modelling, The University of Melbourne), pp. $1-10$.

Vastag, P. H., Thum, P. G., and Niemann Jr., B. J., 1994, Project LOCALIS: implementing LIS/GIS in local government. URISA Journal, 6, 78-83.

Weill, P., and Broadbent, M., 1994, Infrastructure mix and match. Management Information Systems (October), 2-55. 


\section{University Library}

\section{- M M I E E R VA A gateway to Melbourne's research publications}

Minerva Access is the Institutional Repository of The University of Melbourne

Author/s:

Chan, Tai O.;Williamson, Ian P.

Title:

Long term management of a corporate GIS

Date:

2000

Citation:

Chan, T. O. \& Williamson, I. P. (2000). Long term management of a corporate GIS. International Journal of Geographical Information Science, 14(3), 283-303.

Publication Status:

Published

Persistent Link:

http://hdl.handle.net/11343/33988 